2020-08

\title{
Predicting beach rotation using multiple atmospheric indices
}

\author{
Wiggins, Mark
}

http://hdl.handle.net/10026.1/15697

10.1016/j.margeo.2020.106207

Marine Geology

Elsevier BV

All content in PEARL is protected by copyright law. Author manuscripts are made available in accordance with publisher policies. Please cite only the published version using the details provided on the item record or document. In the absence of an open licence (e.g. Creative Commons), permissions for further reuse of content should be sought from the publisher or author. 


\title{
Predicting beach rotation using multiple atmospheric indices
}

\author{
Mark Wiggins ${ }^{1}$, Tim Scott ${ }^{1}$, Gerd Masselink ${ }^{1}$, R. Jak McCarroll ${ }^{1} \&$ Paul Russell ${ }^{1}$
}

1. Coastal Processes Research Group, Plymouth University, Drake Circus, Plymouth PL4 8AA, United Kingdom.

Corresponding author: MarkWiggins.mark.wiggins@plymouth.ac.uk

\section{$\underline{\text { Abstract }}$}

Shoreline change in the form of beach rotation can occur at event to decadal timescales, especially in semi-sheltered embayments with bi-directional wave climates, leading to enhanced coastal vulnerability under predictions of increased sea level rise. Previous studies have shown that phases of winter-averaged atmospheric indices in the North Atlantic correlate with variations in average winter wave height and dominant direction; however, predictions of a localised wave climate and beach rotation from individual climate indices has exhibited limited skill. Here we show that the combination of two major north Atlantic climate indices, the North Atlantic Oscillation (NAO) and West Europe Pressure Anomaly (WEPA), improves the prediction of a wave power directionality index (WDI), known to correlate with beach rotation along the length of a headland bound gravel embayment.

Results using a combination of NAO and WEPA, improves predictions of WDI with an associated $\mathrm{R}^{2}$ of 0.66 , when compared to 0.23 and 0.31 for NAO and WEPA individually. Hindcast (WDIww3) and index predicted (WDIPred) values of the WDI were shown to validate against measured beach rotation from 2008 to 2018 and modelled inshore potential longshore energy fluxes from 1980 to 2018. A long-term historic time series of WDI $I_{\text {Pred }}$ (1906-present) was then hindcast using records of NAO and WEPA. Qualitative validation of long-term beach rotation in response to the WDIPred is achieved with proxy records of beach change in the form of oblique and aerial photography and topographic maps. Low frequency $(\sim 60$ 
years) beach rotation is shown to follow phases of the detrended cumulative WDI $\mathrm{Pred}_{\text {values, }}$ over the period of 1906 to 2018 , linked to the multi-decadal fluctuations in detrended cumulative values of NAO and WEPA. When examined in the context of millennial-scale proxy NAO records, it is clear the recent centurial-scale analysis does not capture past variability and duration. This work has shown that: (1) potential future season ahead forecasts of atmospheric indices may skilfully predict beach rotation in many regions with bidirectional wave climates; and (2) historical analysis highlights the potential past phases of extreme coastal realignment. These new insights will lead to proactive and informed management from local authorities and coastal engineers.

Keywords: Beach rotation, NAO, WEPA, climate indices, atmospheric variability, N Atlantic.

\section{Introduction}

Predicting shoreline change and evolution is an ever growing issue for coastal managers, engineers and communities, particularly in light of observed and forecasted sea level rise (Nicholls et al., 2011). Whilst increases in storminess and significant wave height (Dodet et al., 2010) have been shown to cause significant cross-shore erosion of exposed beaches (Burvingt et al., 2016; Masselink et al., 2016; Scott et al., 2016), beach rotation due to longshore sediment transport under changes in the incoming wave direction (Klein et al., 2002), plays an equally important role in coastal vulnerability for many semi-sheltered embayments with bi-directional wave climates (Ruiz de Alegria-Arzaburu and Masselink, 2010; Wiggins et al., 2019a). Single storm events and annual winter rotational responses can leave embayments depleted of sediment at the up-wave extent, reducing overall beach volume and increasing the risk of damage, flooding and cliff retreat. If the wave climate maintains a bias towards a particular direction over multi-annual to decadal timescales, these 
potential risks increase, due to the lack of recovered beach volumes, reducing the protection offered against damage under storm wave attack.

Understanding the controls that wave power and direction have on beach response has been investigated globally, with phases of atmospheric indices showing strong links to wave height and direction on local to basin wide scales (Barnard et al., 2015; Harley et al., 2017; Ranasinghe et al., 2004). Within the North Atlantic, recent studies have identified both the North Atlantic Oscillation (NAO) and West Europe Pressure Anomaly (WEPA) as playing a significant role in controlling both the winter-averaged wave height and dominant wind directions (Bacon and Carter, 1993; Castelle et al., 2018, 2017; Dodet et al., 2010; Izaguirre et al., 2010; Martínez-Asensio et al., 2016; Plomaritis et al., 2015). Positive phases of the NAO have been shown to predict increased winter wave height and westerly winds in the upper latitudes of the north Atlantic, northward of $52^{\circ} \mathrm{N}$, whilst positive phases of WEPA outscore other indices in predicting increased wave heights southward of this latitude, until the coast of Portugal (Castelle et al., 2018). Along the entire length of the south coast of the United Kingdom $\left(<52^{\circ} \mathrm{N}\right)$, where waves are directionally bi-modal (south-westerly and easterly), Wiggins et al. (2019b) observed that winter NAO and WEPA were best suited to predicting easterly and south-westerly winter-averaged wave power, respectively, with weak or no correlation in their opposite directions. In turn, the beach response for many south-east facing beaches along the same coastline, showed rotation was controlled by the Wave Directional Index (WDI), defined as the standardised winter power balance between the primary and secondary winter wave directions (Wiggins et al., 2019a). Despite the strong correlations between WDI and beach rotation, individually, NAO and WEPA were only weakly positively correlated with the WDI, and only significantly correlated with beach rotation in two of the 22 measured locations. 
Given the current state of winter NAO forecasting (Dunstone et al., 2016; Scaife et al., 2015;

Weisheimer et al., 2017), and the ability to predict several months ahead for the coming winter season, any improvements to our understanding of the relationship between atmospheric indices and morphology could lead us towards season ahead beach response forecasts for rotational sites, a tool that would be welcomed by coastal managers from local to regional scales. Furthermore, an improved relationship between climate variability and beach response could offer the capability to investigate historic beach state, providing a representative indicator of potential future variability, and place the observed contemporary changes into a longer-term context. For example, centurial-scale reconstructions of the NAO (Cook et al., 2002; Faust et al., 2016; Trouet et al., 2012) and the use of proxy records to model the NAO as far back as 3000BP (e.g. Baker et al., 2015), suggest that low frequency fluctuations of significant magnitude have occurred over multi-centurial timescales, many of which have been linked to well documented climate anomalies (e.g. Mediaeval Climate Anomaly, Little Ice Age), causing variations in precipitation, temperature and storminess, potentially driving large scale morphological activity such as sustained coastal dune transgression (Clarke and Rendell, 2006; Jackson et al., 2019). This study aims to investigate whether an improved relationship between climatic indices and winter WDI can be obtained by multivariate analysis, helping to place our current observations of wave climate controls on beach rotation into context with centurial scale fluctuations, allowing for proactive decisions in terms of long-term planning and coastal management.

\section{Regional setting}

Start Bay lies along the south coast of Devon, United Kingdom $\left(50.27^{\circ} \mathrm{N}, 3.65^{\circ} \mathrm{W}\right)$, facing south east into the English Channel. The embayment consists of four interconnected coarse gravel barriers $\left(\mathrm{D}_{50}=2-10 \mathrm{~mm}\right)$, backed by freshwater lagoons and separated at high tides by protruding rocky headlands and wave cut platforms. Aligned from south-west to north-east, 

the bay.

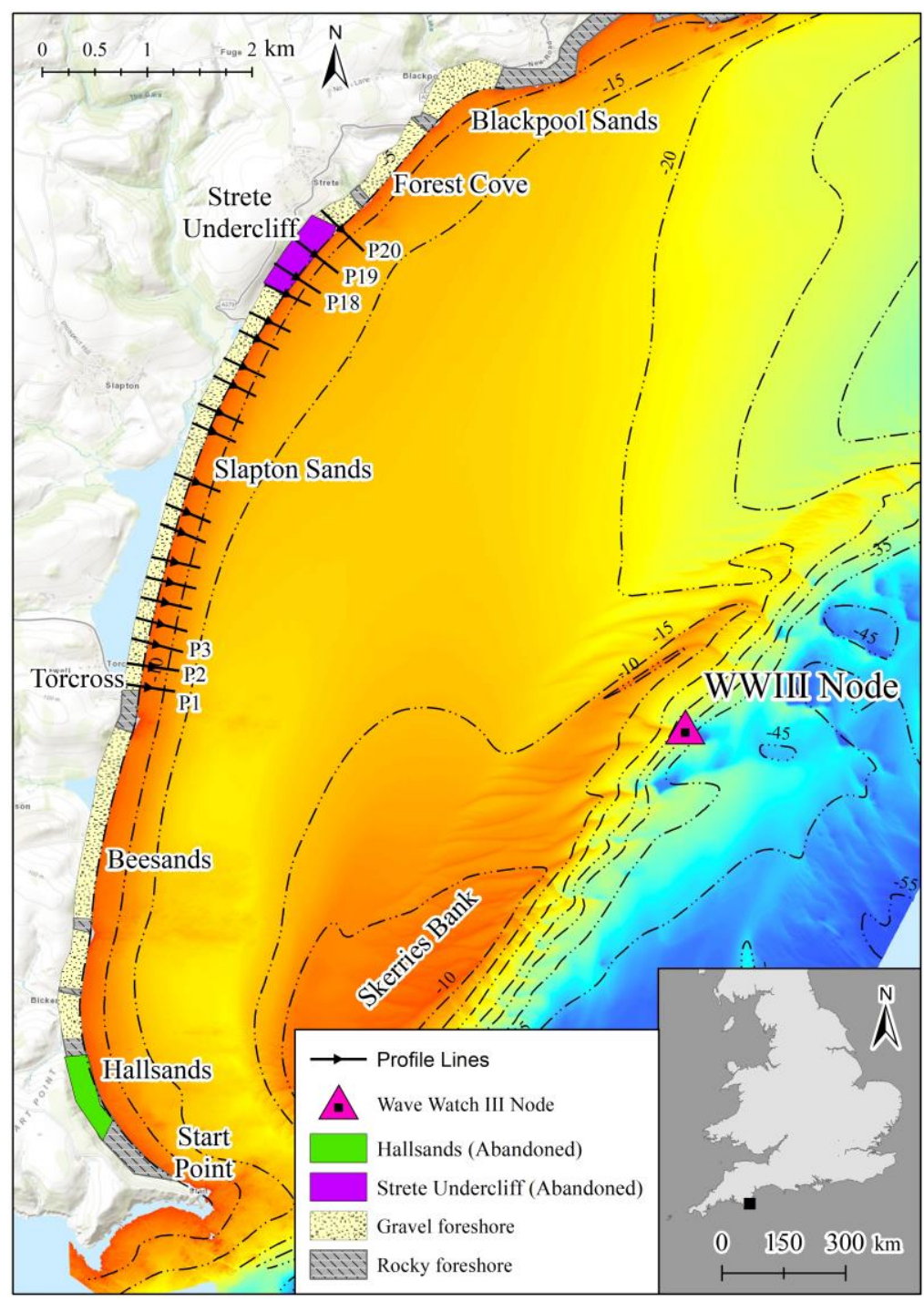

Figure 1. Location map of Start Bay with bathymetric contours (UKHO, 2013) and WWIII (Met Office) model node location. Topographic profile survey line locations are displayed as black arrows. The locations of two abandoned villages are displayed by the coloured polygons located towards the northern and southern ends of the embayment. 
The southerly and easterly wave angles drive northward and southward sediment transport respectively, and the embayment is continually in a state of dynamic equilibrium, with the planform shape rotating in response to the current wave approach. The full embayment sediment cell as a whole, was demonstrated to be closed by Wiggins et al. (2019a), bounded by significant northern and southern headlands; however, beach rotation and exchange of sediment between the individual sub-embayments was observed through headland bypassing under extreme wave conditions (McCarroll et al., 2019) and sustained periods of a particular wave direction (Wiggins et al., 2019a).

Both full-embayment and sub-embayment beach rotation has long been a concern within Start Bay, with significant historical and contemporary examples being the subject of numerous scientific studies (Chadwick et al., 2005; Hails, 1975; McCarroll et al., 2019; Robinson, 1961; Ruiz de Alegria-Arzaburu and Masselink, 2010; Wiggins et al., 2019a, 2019b, 2017). The loss of the old village of Hallsands in 1917 is one of the highest profile cases of coastal erosion impacts in the United Kingdom. Lying at the southern corner of Start Bay (Figure 1), its collapse into the sea during a severe easterly storm followed a sustained lowering of the beach level in the years earlier, largely attributed to the dredging of subtidal beach material between 1897 and 1902 (Worth (1904), cited in May and Hansom (2003)). In addition to the dredging, evidence suggests that beach lowering at this end of the embayment was exacerbated due to a coincidental shift in winter NAO to a sustained positive phase for almost 30 years from the commencement of dredging (1898), leading to increased southerly waves, and clockwise rotation of the beach under prolonged northward sediment transport (Wiggins et al., 2017). Historical accounts of an earlier lost village at the opposite end of Start Bay, suggests the local community may have formed settlements based on the rotation and planform of the beach. Strete Undercliff, a small fishing village formed during the early $17^{\text {th }}$ century (Goodall, 2007) and located at the northern end of Slapton Sands (Figure 1), was 
documented on early nautical maps (Denbigh, 2017), until its subsequent disappearance by 1780 (Stranack, 2017; Waterhouse, 2009), around the time the village of Hallsands (in the south) became more established. Despite the lack of quantitative data from this period, it could be suggested that due to the closed nature of the sediment budget within Start Bay (Wiggins et al., 2019a), variations in multi-decadal phases of wave direction may have influenced the settlement locations of the past and present communities of Start Bay.

More recently, during the winter of 2013/14, Start Bay's beaches experienced significant clockwise rotation under a single winter season characterized by unprecedented southwesterly storm events (Masselink et al., 2015; Scott et al., 2016; Wiggins et al., 2019a), leaving the southern ends of embayments depleted of sediment. This increased the vulnerability of coastal defences at southern beach extremities, and in the following winter years (2015 and 2016), lack of beach volume resulted in the undermining and collapse of sea walls at Torcross, Slapton Sands, and loss of infrastructure including the car park at Hallsands (BBC, 2016).

\section{Materials and methods}

\subsection{Wave data}

WaveWatchIII modelled wave data was obtained for a coastal node offshore of Start Bay (Figure 1) in approximately $20 \mathrm{~m}$ water depth. Total winter wave power was computed at each year for the period of December through March (DJFM), and subsequently split into contributions of the primary (south westerly) and secondary (easterly) directions, designated $P_{1}$ and $P_{2}$, respectively. equation (1) as set out in (Wiggins et al., 2019a); 
159 where $\left(P_{1}-P_{2}\right)$ is the difference in wave power between the primary and secondary wave

160 directions, $\overline{\left(P_{1}-P_{2}\right)}$ is the long-term mean and $\sigma\left(P_{1}-P_{2}\right)$ is the long-term standard

161 deviation of that difference. Positive (negative) values of the WDI represent winter periods

162 where the wave climate was more southerly (easterly) than average.

\subsection{Atmospheric indices}

164

Winter averaged (DJFM) atmospheric index values for the station-based NAO (based on the difference of normalized sea level pressure (SLP) between Lisbon, Portugal and Stykkisholmur/Reykjavik, Iceland since 1864) were obtained from The Climate Data Guide (downloaded from the National Center for Atmospheric Research, https://climatedataguide.ucar.edu/). Additionally, values of the West Europe Pressure Anomaly (WEPA) were obtained via hindcasts of SLP between s Valentia (Ireland) and Santa Cruz de Tenerife (Canary Islands), as developed by Castelle et al (2017) from Twentieth Century Reanalysis data (https://www.esrl.noaa.gov/psd/). Despite SLP derived NAO records being available as far back as the mid to late 1800 s, and proxy reconstructions (described later in section 5) going even further up to 3000 years before present, records of WEPA only date back to 1906 due to limited SLP records and inconsistent hindcasts beyond this.

Previous studies along the entire length of the south coast of England (Wiggins et al., 2019b) have shown that individual wave power contributions from the primary and secondary wave directional modes are well correlated with WEPA and NAO respectively. Winter values of the WDI for Start Bay are positively correlated with both NAO and WEPA, suggesting that a combination of the two indices may improve the predictive skill at this location. To assess 
this further, an empirical stepwise multiple linear regression (SMLR) model was constructed using both NAO and WEPA.

\subsection{Modelled longshore sediment flux}

A look-up table modelling approach was applied by McCarroll et al. (2020), for the period $1980-2018$, to transform offshore wave conditions to breakpoint values in order to estimate alongshore wave power and potential longshore sediment flux within the Start Bay embayment. The estimated flux is 'potential' as the model assumes unlimited sediment availability. Bathymetry for the model was obtained using inshore multibeam (Wiggins et al., 2019a), combined with offshore multibeam from 2013 (UKHO, 2013). To generate the inshore wave conditions for the look-up model, Delft3D-WAVE was run in stationary mode for 400 scenarios, covering the full range of naturally occurring boundary wave conditions. Boundary conditions for a 1980-2018 wave time series were obtained from a coarse-grid hindcast model (WaveWatchIII, Met Office). These boundary conditions were transferred to points along the 14-m depth contour using the look-up table approach. A simple refractionshoaling parameterisation (Van Rijn, 2014) was used to transform waves from 14-m depth to the break point, with nodes at $25-\mathrm{m}$ spacing. The breaking wave conditions were used to estimate alongshore wave power using linear wave theory. Alongshore sediment flux was estimated using the CERC equation (USACE, 2002), for a range of K-value coefficients (0.04 to 0.26$)$. The output from the look-up model is a 38 -year time series of longshore wave power and potential sediment flux, which was validated against prior model results and field observations (McCarroll et al., 2019). A detailed description of the model setup and forcing can be found within McCarroll et al. (2020). Total winter transport was summed for the DJFM months, and at each location, correlations were drawn between both the observed WDI and the predicted WDI. 
Since 2006, monthly RTK-GPS cross-shore profile surveys of Slapton Sands have been conducted by the University of Plymouth, labelled from south to north as "P1" to "P20", with average spacings of $250 \mathrm{~m}$ (Figure 1). Pre-winter autumn and post-winter spring surveys along the length of the beach provide alongshore averaged volume change at the southern (P1 to P3) and northern (P18 to P20) ends, both of which have been shown to linearly correlate with winter values of the WDI (Wiggins et al., 2019a). A rotation index, shown in equation (2), was computed for winter change as per the methodology in Wiggins et al. (2019b), by subtracting the normalized winter volume change $\left(d V_{i}\right)$ from the southern end of the beach from the northern end, such that;

$$
\text { Rotation Index }=d V_{i}(\text { north })-d V_{i}(\text { south })
$$

Positive values of the rotation index represent periods of clockwise northwards rotation and negative values indicate winters where anti-clockwise southward rotation has occurred.

\subsection{Photographic rotation index}

Despite the availability of high accuracy beach surveys from 2007 onwards, prior to this date, quantitative records of beach volume change are scarce. Any surveys that have been found lack consistency in both temporal and spatial frequency as well as method. As such, metrics for beach rotation have been obtained via proxy records of historic photographs, Ordnance Survey (OS) topographic maps and limited aerial photography. For the purposes of this study, beach width at Torcross (at the southern end of the Slapton Sands embayment, Figure 1) was chosen based on the availability of historical photographs taken from the same location (a prominent headland just south of the sea wall), and the significant negative correlation between measured beach width/volume and the WDI over the period of 2007 to 2018 (Wiggins et al., 2019a). Additionally, this location of the beach was identified in Wiggins et 
al. (2019a) as being indicative of beach rotation, with a significant negative correlation with the northern end of Slapton Sands, implying beach width at one end of the embayment can be used as an indicator of beach rotation. In total, 32 oblique photographs were used, taken from

232 the same location (dating from 1875 to 2019), without the need for rectification. In addition, 233 seven sets of aerial photography (1944 to 2017), and three geo-rectified OS maps with high and low water contours $(1887,1852$ and 1983) were also used.

To assess historical changes in beach width with the limited dataset available, an integer scale of -2 ("Very Narrow") to +2 ("Very Wide") was assessed qualitatively (as shown in Figure 7), based on manual interpretation of the entire dataset, providing a simple, categorical metric of relative beach width for each dated photograph and map for this location. The range of observed beach widths was taken into account in devising the scale, from the most accreted in 1890 , to most eroded in 2016.

\section{Results}

\subsection{WDI predictions from atmospheric indices}

Initial exploration of the relationships between the WaveWatchIII derived WDI (WDIWw3) with NAO and WEPA, for a 38 year timeseries between 1980 and 2018 show statistically significant $(\mathrm{p}<0.05)$ positive correlations (Figure 2); however, relative skill in predicting the

247 WDIww3 is low for both indices $\left(\mathrm{R}^{2}<0.31\right)$. 
249
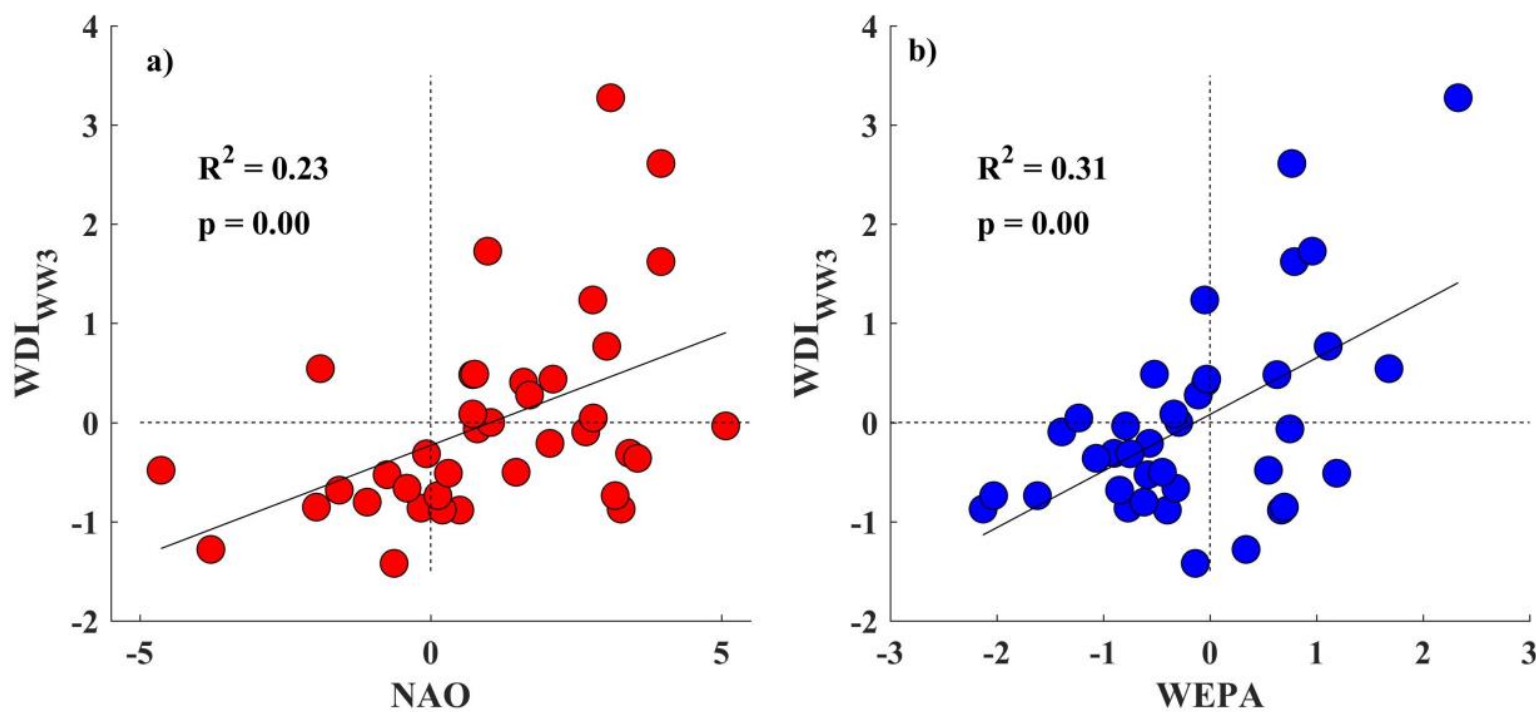

Figure 2. Correlations between winter averaged atmospheric indices NAO, WEPA and the WDI ww3 $_{3}$ for the period of 1980 to 2018.

A SMLR model was created using both NAO and WEPA as predictor variables, with results suggesting that a regression model computed from a combination both NAO and WEPA variables provide improvement in the skill of predicted WDI (WDI $I_{\text {Pred }}$ ). First and second order polynomial models were tested, in addition to two-term exponential regressions, with a linear fit offering the most explanatory power in predicting the WDIPred, such that;

$$
\mathrm{WDI}_{\text {Pred }}=\beta_{0}+\beta_{1} N A O+\beta_{2} W E P A
$$

Where $\beta_{0}$ represents the intercept and $\beta_{1}$ to $\beta_{2}$ are coefficients of the predictor variables, with their estimates, confidence bounds and statistics shown in Table 1.

Table 1: SMLR model statistics for the predictor variables used for modelling winter values of the WDI.

\begin{tabular}{cccccccc}
\hline Coefficient & Predictor & Estimate & Lower (95\%) & Upper (95\%) & SE & tStat & pValue \\
\hline$\beta_{0}$ & (Intercept) & -0.19 & -0.41 & 0.03 & 0.11 & -1.78 & 0.083 \\
$\beta_{1}$ & NAO & 0.29 & 0.19 & 0.38 & 0.05 & 6.11 & $5.54 \times 10^{-7}$ \\
& & & & & & & \\
$\beta_{2}$ & WEPA & 0.69 & 0.48 & 0.90 & 0.10 & 6.74 & $8.36 \times 10^{-8}$
\end{tabular}


262 Overall improvements to the predictive skill of combining the indices are shown in Table 2, 263 with the RMSE reducing from 0.9 when using NAO alone, to 0.60 when using NAO and 264 WEPA. Similar improvements are seen when assessing the $\mathrm{R}^{2}$ value, with an improvement of 265 from 0.23 to $0.66\left(\mathrm{p}=4.71 \times 10^{-10}\right)$. The coefficients for the two indices (Table 1) show that 266 WEPA contributes more (0.69) to the overall predicted values of the WDIPred than NAO $267(0.29)$. predicting winter values of the $\mathrm{WDI}_{\mathrm{Pred}}$.

\begin{tabular}{cccc}
\hline Predictor Terms & $\boldsymbol{R M S E}$ & $\boldsymbol{R}$-squared & $\boldsymbol{P}$-value \\
& & & \\
\hline NAO & 0.90 & 0.23 & $2.39 \times 10^{-3}$ \\
WEPA & 0.86 & 0.31 & $3.15 \times 10^{-4}$ \\
NAO + WEPA & 0.60 & 0.66 & $5.08 \times 10^{-9}$
\end{tabular}

271 Outputs of WDIPred for the period of the modelled wave data (Figure 4) show the addition of 272 both indices reproduce the winter WDIww3 values with an $\mathrm{R}^{2}$ value of 0.66 . 


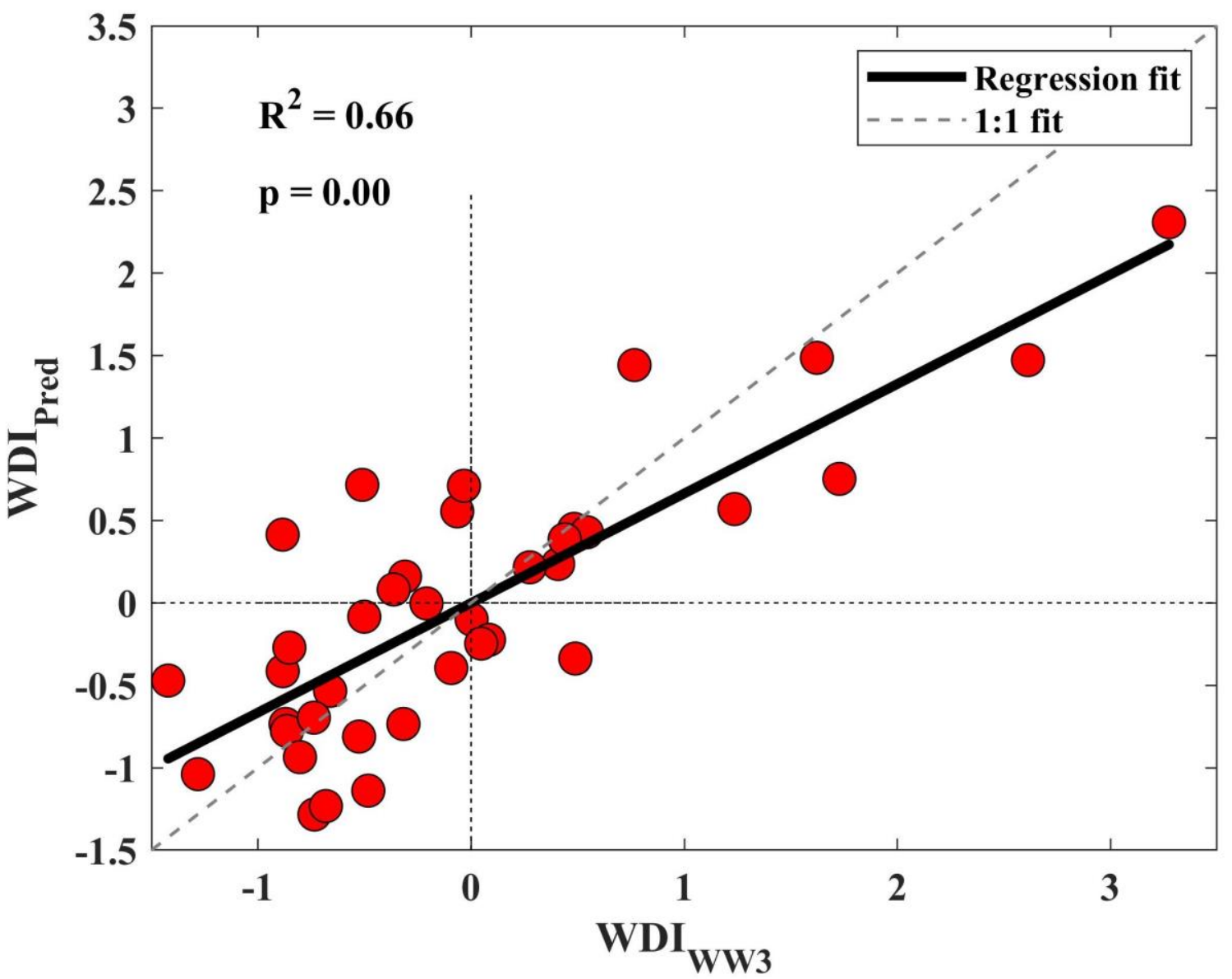

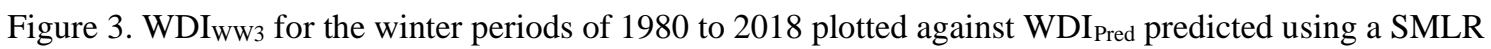
model of winter atmospheric indices. The regression fit is shown as the bold line, whilst the 1:1 fit is displayed as the dashed grey line.

Using the regression model, values of NAO and WEPA are used to hindcast the WDI Pred $_{\text {back }}$ to the beginning of the record of atmospheric indices (1906). The predicted output can be seen in the top panel of Figure 4, with the accumulated value of the WDIPred plotted in the middle panel.

Clear inter-annual variation can be seen within the long-term WDIPred values (Figure 4 a); however, there are periods of sustained negative or positive winter values, persisting for up to five years in a row (e.g. 2008 to 2013). Despite the high $\mathrm{R}^{2}$ value between the $\mathrm{WDI}_{\mathrm{Ww}}$ and the WDIPred hindcast from atmospheric indices (for the overlapping period of 1980 to 2018, Figure 3), there are some years where the sign of the WDIPred is opposite to the WDIww3, e.g. 
2000 to 2003 . This can be attributed to years where winter averaged values of NAO and

287 WEPA are low (close to zero) or opposite in sign, leading to the larger of the two indices impacting the WDIPred. In addition, although the regression analysis was conducted using a

289 linear relationship, the fit between winter averaged climate indices and WDIww3 is not

290 perfectly linear, especially for extremely high values of NAO and WEPA within the limited

291 37-year timeseries (Figure 2a and b). This explains why the regression model under predicts

292 the value of the WDI $\mathrm{Wred}_{\text {for }}$ some years; however, in the majority of cases where the WDIww3

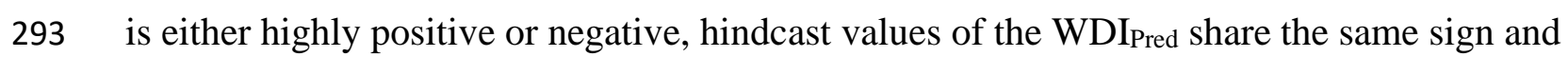

294 are also larger in magnitude relative to the overall time series average.

295 The annual hindcast WDIPred values have a limited trend over the last 113 years; however, the

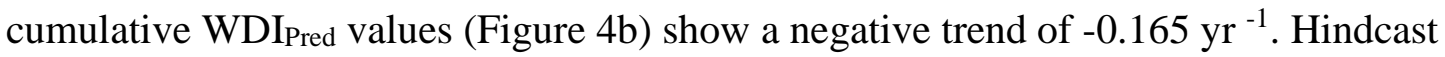
cumulative WDIPred was detrended by removing the linear mean trend using a least-squares regression, to highlight the fluctuations in the cumulative WDIPred values over time. The detrended values of the cumulative WDIPred (Figure 4c, bottom panel) indicate that there is potential periodicity in phases of positive and negative WDIPred. 

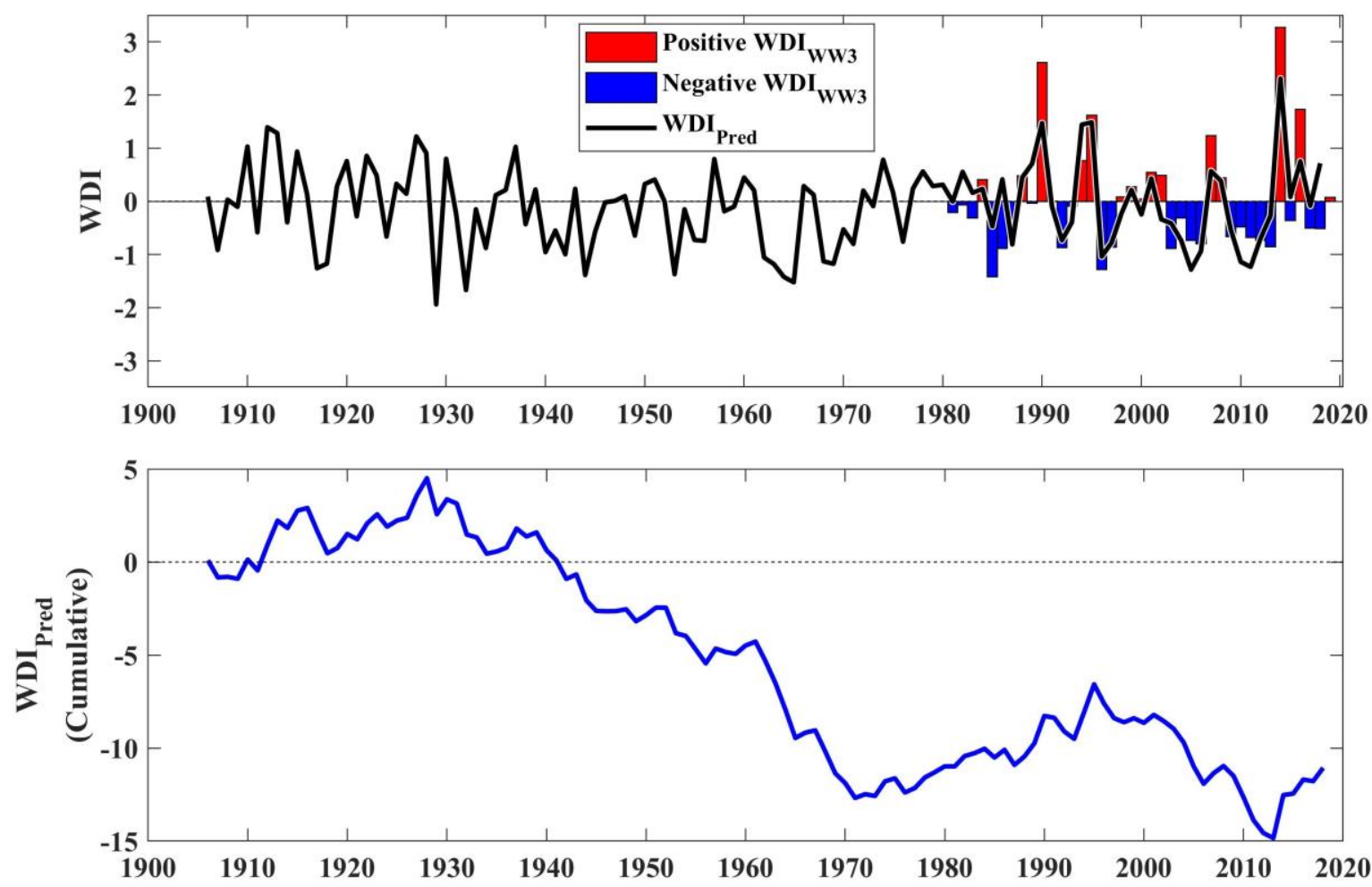

302

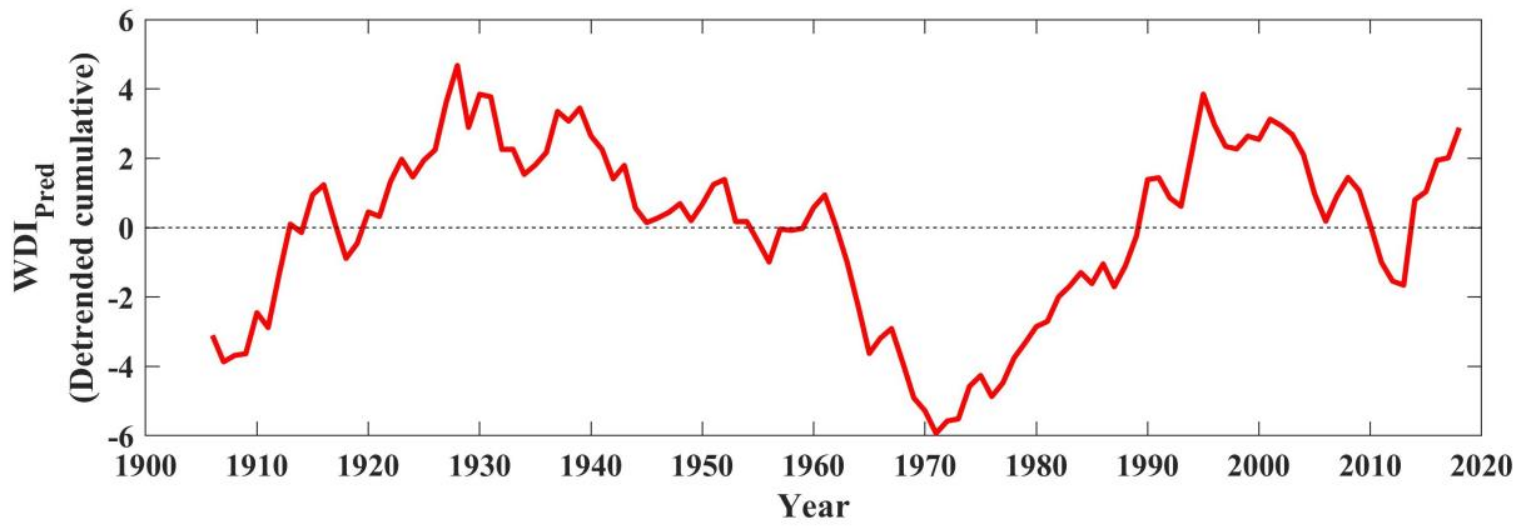

Figure 4. a) SMLR modelled WDI Pred values from atmospheric indices NAO and WEPA, predicted back to 1906, as well as the values of WDI Ww3 $_{3}$ as obtained from the WaveWatchIII model. b) The cumulative WDI Pred values from 1906 to 2018, as predicted by the SMLR model of NAO and WEPA. c) The detrended cumulative values of WDI Pred from 1906 to 2018.

\subsection{Modelled longshore sediment flux}

To examine the relationship between the two different offshore WDI parameters (WDIww3 and $\left.\mathrm{WDI}_{\text {Pred }}\right)$ and transport rates within the embayment, potential along-shore sediment flux was computed for a series of six fixed shoreline positions (Figure 5.a), using an inshore wave 
transformation model comprising real bathymetry (see further, McCarroll et al. (2020)). Total potential winter transport totals (Figure 5.b, e, h, k, n, q) were compared with WDIww3 values for the period of 1980 to 2018. In all locations, significant positive correlations are observed between the WDIww3 and directional sediment transport (Figure 5.c, f, i, 1, o, r), with the strongest correlation being at Strete $\left(R^{2}=0.84\right)$, the northern end of Slapton Sands (Figure

316 5.f). Other nodes located in the northern sections of the embayment show a balance of

317 northward (southward) transport under highly positive (negative) WDIww3 winters, whereas

318 almost all winter WDI ww3 conditions drive northward transport at Hallsands in the far south 319 of the embayment.

320 The positive correlations throughout the bay suggest that the WDI $\mathrm{ww}_{3}$ calculated at the offshore model node is an adequate proxy of the balance of inshore wave directions, responsible for driving sediment transport and beach rotation within the embayment.
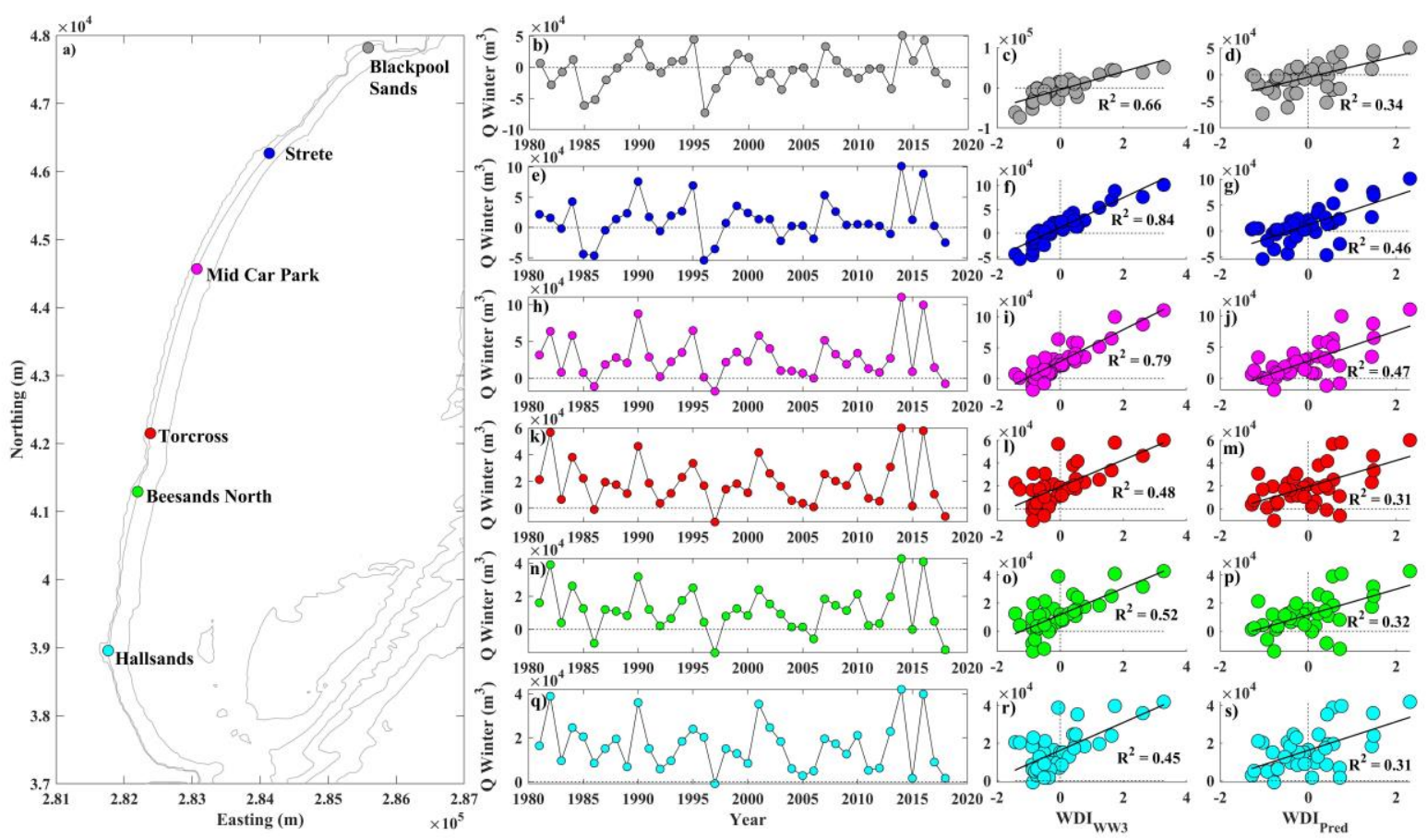
Figure 5. a) location map of inshore nodes at which total potential winter sediment flux has been calculated, b) total potential winter alongshore sediment flux at Blackpool Sands, e) Strete, h) Middle car park, k) Torcross, n) Beesands North and q) Hallsands. Panels c), f), i), 1), o) and r) show the correlation between the WDIww3, and longshore sediment transport at the six locations, whilst panels d), g), j), m), p) and s) show the same correlations but with values of WDI $\mathrm{Wred}_{\text {. }}$

In addition to the comparisons between modelled sediment transport and $\mathrm{WDI}_{\mathrm{Ww}}$, the same comparison was conducted against values of the WDIPred, as produced by the SMLR (Figure $5 \mathrm{~d}, \mathrm{~g}, \mathrm{j}, \mathrm{m}, \mathrm{p}$ and s). At all sites, weaker but similarly positive correlations were observed, with all results being significant at the $95 \%$ confidence interval, highlighting that the WDIPred computed from climate indexes is a suitable proxy for estimating flux at the shoreline. Although the WDIPred values are consistently lower than the WDIww3 (in part due to the standardized nature of the WDI wave power parameter)

\subsection{Validation against beach surveys and historical records}

To demonstrate the potential application of WDIPred in predicting beach rotation, correlations with contemporary and historical beach rotation are presented. Similar to previous studies of both Slapton Sands and other locations in the south west, values of the WDIww3 are well correlated with the rotation index (defined in eq. 2) for the period of 2008 to 2019 , derived from topographic survey data. The sign of the rotation index tracks well with the sign of WDIww3 (Figure 6.a), whilst the linear correlation of the two is significant and strong $(\mathrm{R}=$ $0.77, \mathrm{p}=0.00$, Figure 6.b). Similarly, the correlation between the WDIPred and rotation index is positive $(\mathrm{R}=0.47)$, despite not being statistically significant at the $95 \%$ confidence limit; however, it is observed that the correlation is much stronger and statistically significant $(\mathrm{R}=$ $0.74, \mathrm{p}=0.01$ ), if the winter change from $2017 / 18$ (due to a single easterly event) is removed as an outlier (discussed further in Section 5). 

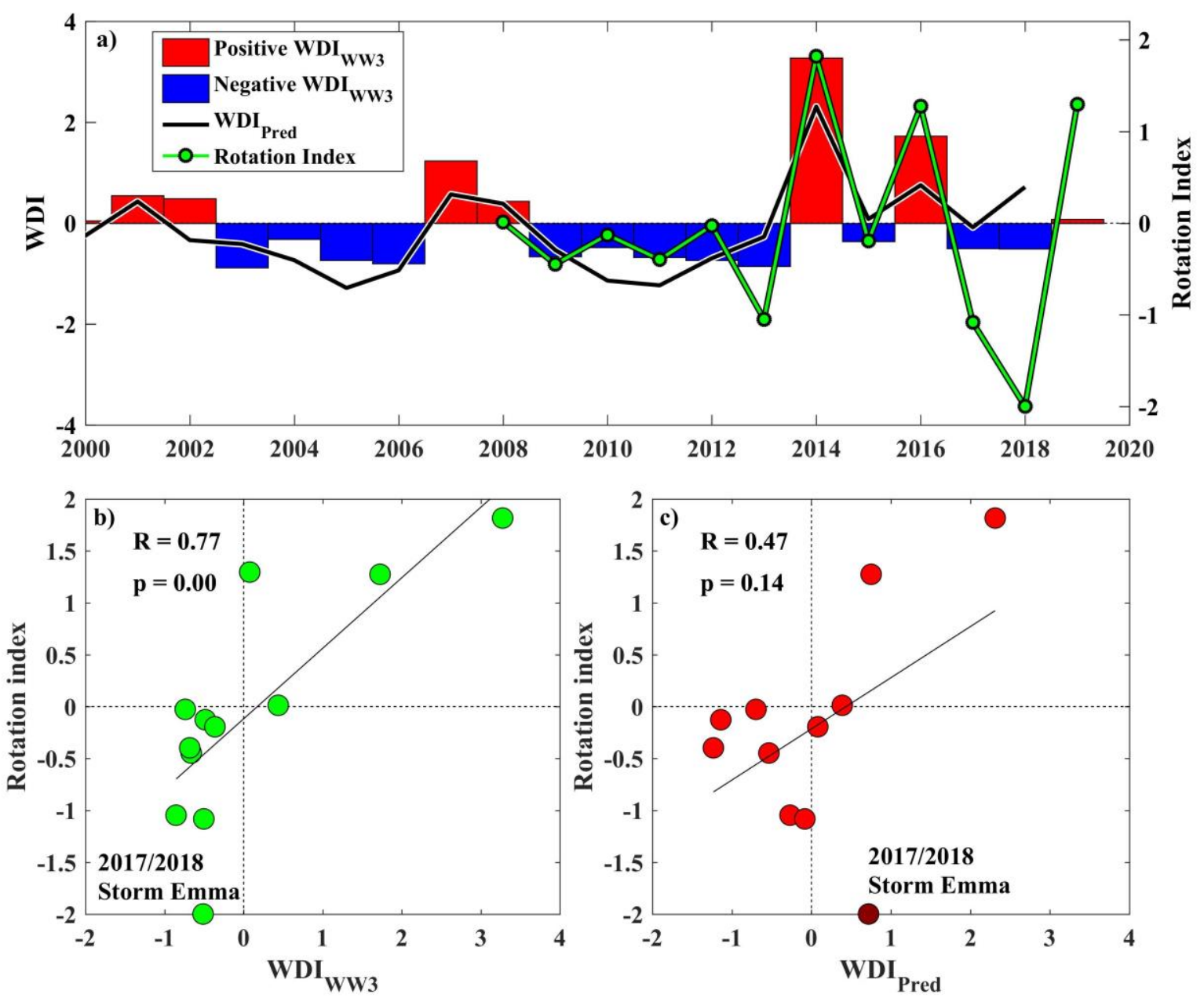

Figure 6. a) Time series of short term ( 20 years) $\mathrm{WDI}_{\mathrm{Ww} 3}$ values, shown by the red and blue bars, overlaid with WDI $_{\text {red }}$ from the NAO and WEPA SMLR model, shown as the black line. The rotation index (green line) over the period of 2008 to 2019, derived from measured winter change (November to March) in beach volume at opposing ends of Slapton Sands, with positive (negative) values indicating northward clockwise (southward anticlockwise) beach rotation. b) Correlation between $\mathrm{WDI}_{\mathrm{ww}}$ and winter rotation index for the period of 2008 to 2019. c) Correlation between winter WDI Pred $_{\text {and }}$ the winter rotation index for the period of 2008 to 2018 .

The lack of consistent high-quality shoreline data before 2006 means proxy records are the only possibility for validation of the longer-term WDIPred values. Time series of the qualitative beach width assessment for Torcross and the detrended cumulative WDIPred values for the period spanning 1906 to 2019 are shown in Figure 7.a. The beach appears widest during the last decade of the 1800 s, then beginning to narrow up to the 1920 's, remaining a similar width in photographs and maps until around 1945. A period of beach widening then 


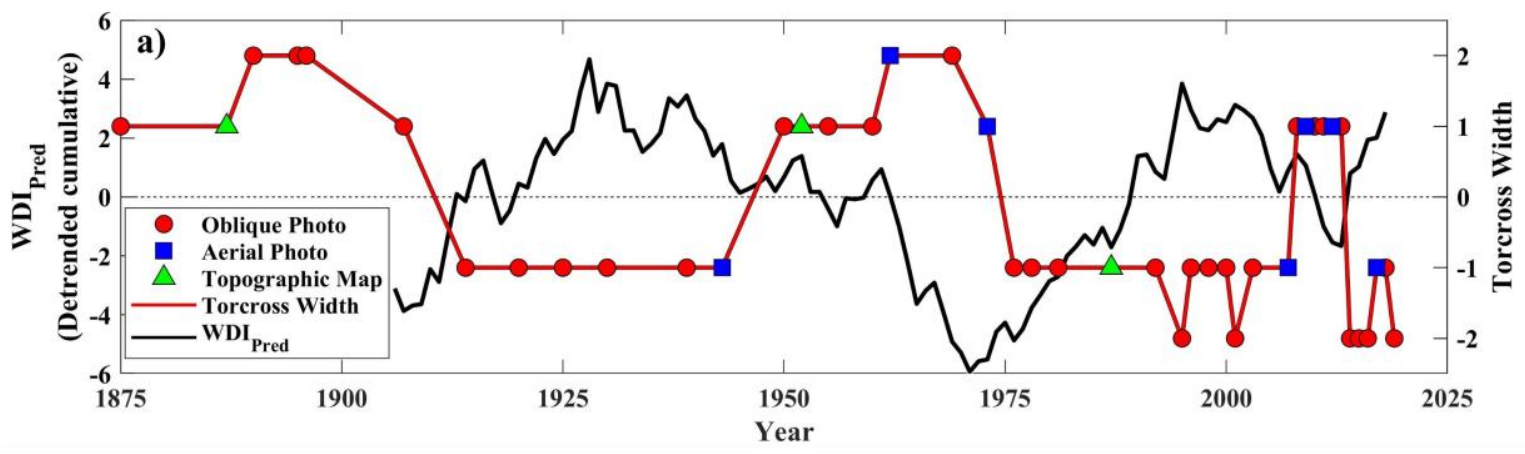

b) 1890 - Very wide
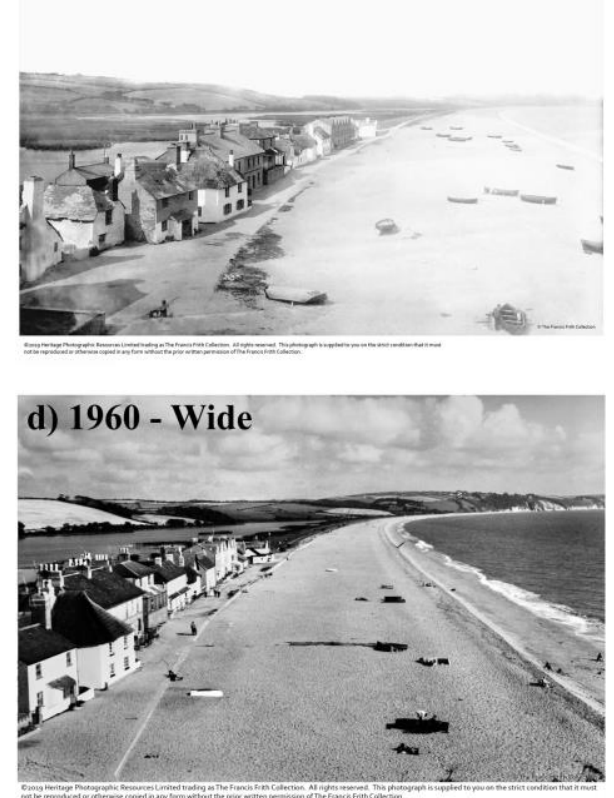

c) 1920 - Narrow

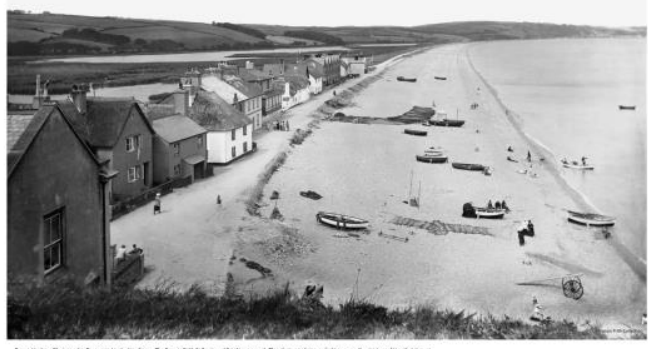

e) 2016 - Very Narrow

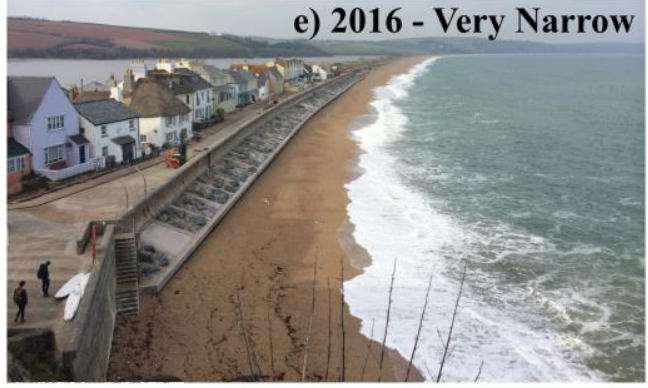

Figure 7. a) Detrended cumulative values of the $\mathrm{WDI}_{\text {Pred }}$ (left axis) from 1906 to 2018, overlaid on the right axis is a qualitative assessment of beach width at Torcross (southern end of Slapton Sands), with positive values indicating a wide beach, suggesting southward sediment transport and anticlockwise beach rotation, whilst negative values indicate a narrower beach, signifying a period of potential northward sediment transport and clockwise beach rotation. b) Photos of Torcross taken in 1890, c) 1920, d) 1960 (Copyright The Francis Frith Collection) e) 2016 (Copyright G. Masselink), showing different beach widths throughout the last 200 years.

373 Both beach width and detrended cumulative $\mathrm{WDI}_{\text {Pred }}$ values display low frequency fluctuations over the last 113 years, with beach width appearing to narrow during periods of 
cumulative positive WDI $\mathrm{I}_{\text {red }}$ and widen during sustained negative phases (Figure 7.a). Longterm detrended cumulative values for the WDIPred as well as the NAO and WEPA were computed and the results are displayed in Figure 8.
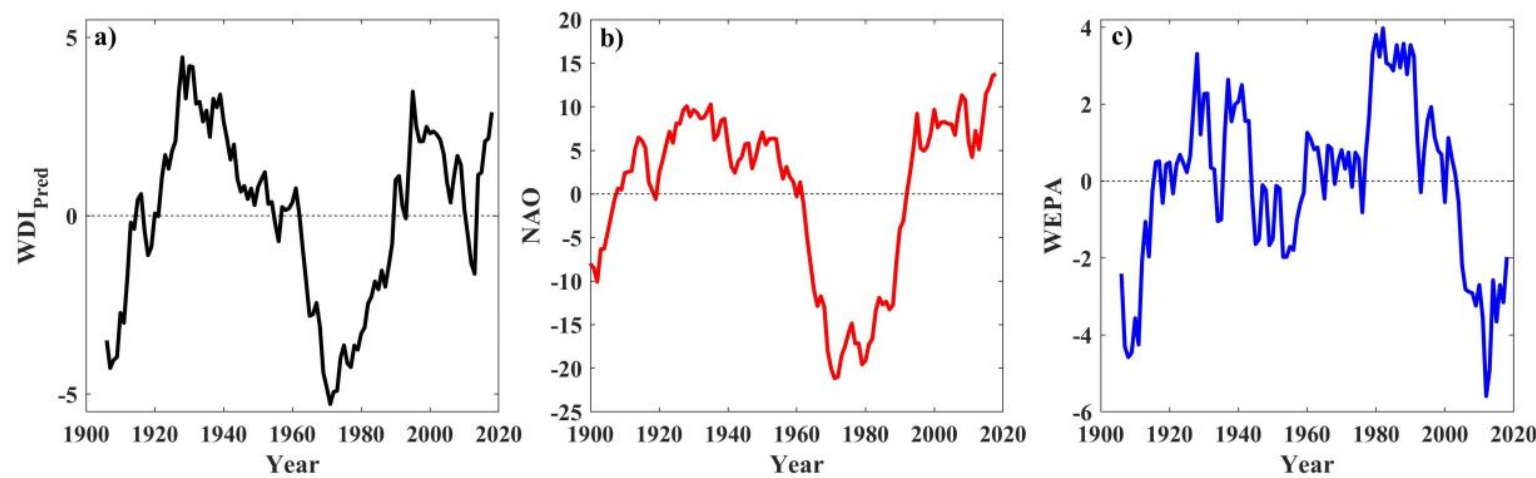

Figure 8. Detrended cumulative values of winter averaged a) $\mathrm{WDI}_{\text {Pred }}$, b) NAO and c) WEPA.

For the $\mathrm{WDI}_{\text {Pred }}$ values (Figure 8.a), the data appears to show a multi-decadal variation in cumulative positive and negative phases, whilst the NAO (Figure 8.b) and WEPA (Figure 8.c) display similar scale variations (Figure 8.c).

\section{Discussion}

This study has shown that combining two major winter-averaged climate indices, NAO and WEPA, in a SMLR model significantly improves skill when trying to predict winter-averaged offshore directional wave climate (WDI), when compared to using the individual indices.

Given that the WDI is key predictor of the magnitude and direction of beach rotation at this, and many similar sites along the length of the southern UK coastline (Wiggins et al., 2019b), the ability to forecast its value from two significant indices represents a step forward in assessing the accuracy in historical records of beach rotation, and the future potential to predict wave climate and morphological behaviour at seasonal to centurial timescales. Whilst previous studies have been able to link changes in atmospheric variability to deviations in wave height or direction (Barnard et al., 2015; Burvingt et al., 2018; Castelle et al., 2018, 
2017; Dodet et al., 2010; Harley et al., 2017; Ranasinghe et al., 2004), the combination of multiple indices for direct calculation of a bi-directional wave climate parameter for opposing directions is unique.

Both the WDIww3 and WDIPred were shown to correlate with winter integrated potential longshore transport rates throughout the embayment (McCarroll et al., 2020). Statistically significant $(\mathrm{p}<0.05)$ correlation coefficients for $\mathrm{WDI}_{\mathrm{Ww} 3}$ and $\mathrm{WDI}_{\text {Pred }}$ ranging from 0.67 to 0.92 , and 0.56 to 0.68 , respectively, show that the WDI calculated for a single point offshore is a robust proxy for the inshore wave climate and sediment transport. Similar to this study, significant correlations were found by Splinter et al. (2012) between yearly modelled net longshore transport rates and positive phases of the Inter-decadal Pacific Oscillation (IPO) and the Southern Oscillation Index (SOI); however, regression models combining both indices required a five-year smoothing average of both predictor and response variables, in addition to separate model equations for positive and negative phases of the IPO, incorporating different coefficients and predictor values at different time lags. The simplicity of the SMLR model used in this study, suggests that where WDI calculations are well correlated with beach rotation (Wiggins et al., 2019a, 2019b), similar analysis can be conducted at other rotation dominated sites.

The results of Section 4.3 show the rotation index of Slapton Sands (as calculated from $>10$ year topographic survey record) is well correlated with values of the WDIww3, but not significantly correlated with the atmospheric index based WDIPred values predicted by the model over a 10-year period of observations. Further investigation into the limited dataset showed that the winter of 2017/18 featured a large single easterly storm event (Storm Emma, further description in (McCarroll et al., 2019)) which caused a significant counter clockwise rotation of the beach at the end of the winter season (March $2^{\text {nd }}$ 2018). The morphological response was observed in the anti-clockwise rotational beach record and the observed 
negative $\mathrm{WDI}_{\mathrm{Ww} 3}$ value $(-0.51)$; however, it was not reflected in the positive winter averages of NAO and WEPA (0.30 and 1.17 respectively). As a result, such values of atmospheric indices resulted in the model predicting a positive WDIPred value $(+0.70)$, suggesting a more southerly than average dominance of wave power. That winter also stands out as having the highest anti-clockwise rotation index during the observational period, so its impact on reducing the strength of the correlation coefficient is substantial.

Clearly single extreme events such as this can cause significant beach rotation and substantial damage to infrastructure, and whilst the $\mathrm{WDI}_{\text {Pred }}$ is shown to correlate well with beach rotation when the 2017/18 winter is removed from the analysis $(\mathrm{R}=0.74 \mathrm{p}=0.01)$, ignoring potential outliers of the general trend presents problems in application within a coastal management setting. If a longer period of accurate morphological survey data was available, better understanding of the skill and limitations of the relationship between WDIPred and beach rotation could be obtained.

Beyond the immediate correlations between both winter WDI values and recent multi-annual beach rotation, it is interesting to examine the detrended cumulative record of WDIPred as conceptually it provides insights into the rotational state of the embayment. Using the SMLR model a hindcast record of $\mathrm{WDI}_{\text {Pred }}$ shows low frequency ( $\sim 60-70$ years) multi-decadal fluctuations over the last century (Figure 8), driven by combined changes in the cumulative values of winter NAO and WEPA. Although the methodology for constructing a proxy record of observed beach rotation is quantitatively limited (i.e. manual interpretation of southern beach width from photography and topographic maps), it does present a qualitative coherence with the periodicity in the long-term cumulative WDIPred values (Figure 7a). Temporal gaps and lack of consistency in the seasonal timing of photographs may lead to aliasing of higher frequency variations in beach width, but the longer-term signal presented in the historical record shows a clear coherence with the detrended cumulative WDIPred values, providing 
some validation for using detrended cumulative WDI $\mathrm{Pred}_{\text {in }}$ this context. Several decades of the last century which show a positive phases in detrended cumulative WDIPred values (e.g. 1900 to 1930; sustained southerly winter waves) coincide with periods of beach narrowing (clockwise rotation), whilst phases of sustained negative detrended cumulative WDIPred values (e.g. 1940 to 1970; higher percentage of easterly winter waves) coincide with beach widening (anti-clockwise rotation). Current improvements to shoreline detection from satellite images dating back to the 1980s, could provide the extended datasets required (e.g. Vos et al., 2019), and would further assist in validating regression models of atmospheric indices and their control on wave climates and beach response.

Successive winters of the same $\mathrm{WDI}_{\text {Pred }}$ sign (positive or negative) may drive cumulative beach rotation in a particular direction or maintain the planform shape if already rotated. Event-scale wave action can cause rapid changes to the beach profile and planform shape, and reversals of wave direction have been shown to quickly counter-rotate the embayment's of Start Bay (McCarroll et al., 2019; Ruiz de Alegria-Arzaburu and Masselink, 2010; Wiggins et al., 2019a); however, this study has identified that multi-decadal trends in the detrended cumulative WDIPred, are mirrored in beach rotation proxies over the last 113 years. Such multi-decadal beach rotation patterns have been identified in other locations over a comparable time period, such as the south coast of Pembrokeshire, Wales, UK, with similar correlations found between wave angle variations driving beach rotation under contrasting phases of the NAO (Thomas et al., 2013). The longer-term trends in cumulative WDI values appear to dictate the general planform state of Start Bay, indicating that within the next 100 years, a continued upward trend in cumulative WDI values, or a potential phase shift into a sustained negative period may lead to sustained clockwise rotation or reversal and anti-

467 clockwise rotation. 
To place the observed contemporary changes in context with long-term reconstructions of the

469

470

471

472

473

474

475
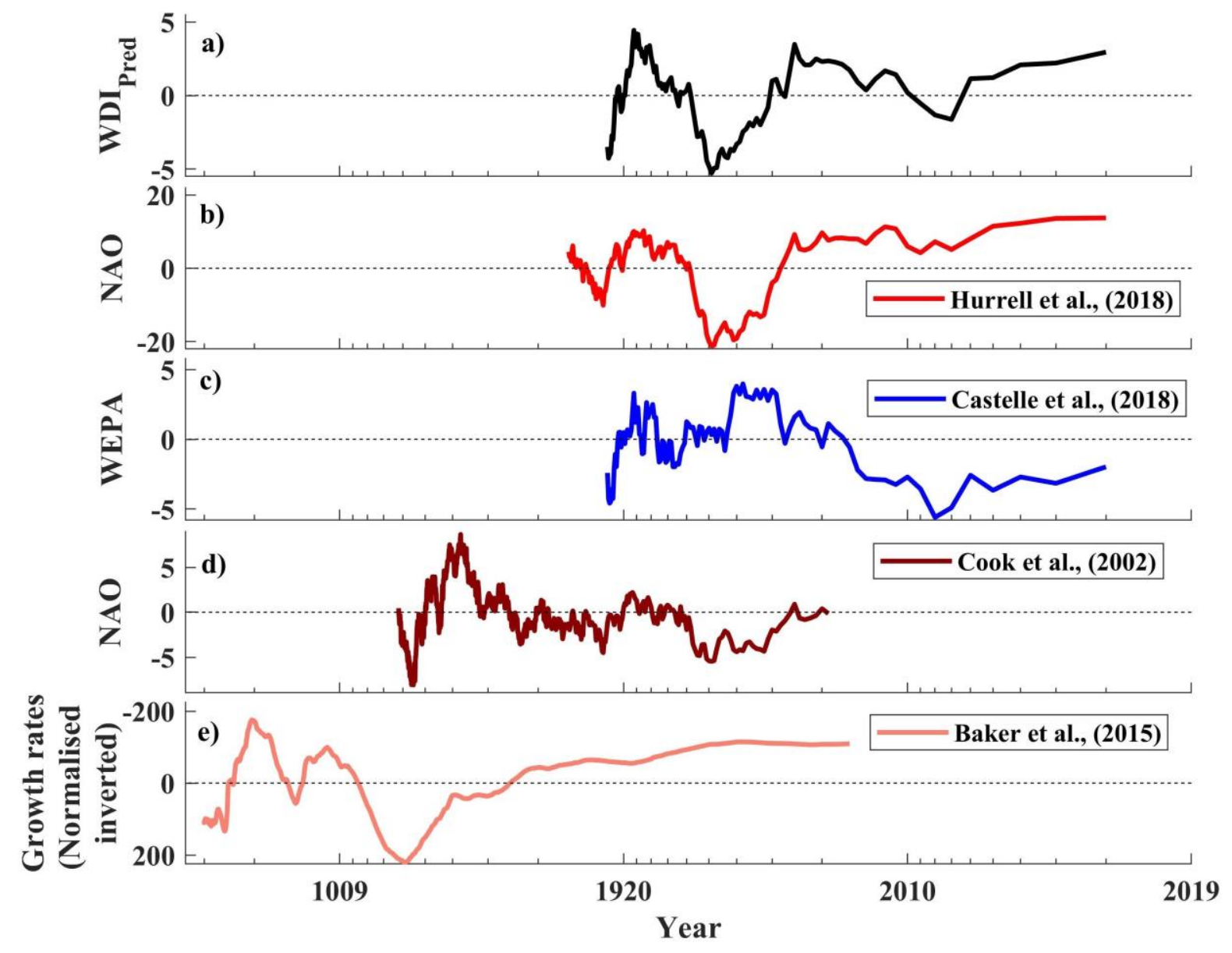

476

NAO, detrended cumulative values of the WDIPred, NAO and WEPA from the current study are plotted on a log time scale in Figure 9. a, b, and c. For comparison, detrended cumulative values of two extened NAO reconstructions are also presented. The first (Figure 9. d), dating back to 1400, is derived from tree-ring and ice-core proxies from Cook et al. (2002)The second (Figure 9. e) is presented as a $~ 3000$ year record of detrended cumulative normalised stalagmite growth rates (Baker et al., 2015), inverted for ease of comparison, with high growth rates representative of drier conditions, reflective of negative NAO phases.

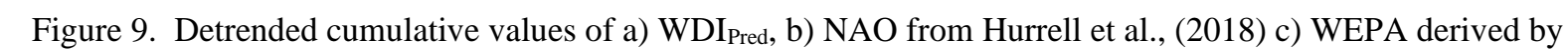
Castelle et al., (2018), d) long-term NAO reconstructions from Cook et al., (2002), e) normalised stalagmite growth rates (inverted) from Baker et al., (2015). Time in year date (A.D.) is presented on a log scale. 
Both additional records demonstrate sustained multi-decadal to multi-centurial phases of significant magnitude which have been confirmed by several other authors (e.g. Faust et al., 2016; Trouet et al., 2012). These observed fluctuations are of significantly greater scale and duration than those exhibited within the 113 years assessed in this study. Long-term variations in NAO have seen noticeable climate shifts identified in Europe over the last 2000 years, including a relative warming during the MCA ( 800 to 1300 A.D.) due to persistent positive NAO (Trouet et al., 2009), as well as a cooler period during the LIA ( $1400-1850$ A.D.) linked to a persistent negative NAO phase (Luterbacher et al., 2002). European coastal response to these changes has been documented, with large-scale dune growth and inland sand migration evidenced during the LIA under negative NAO conditions, due to increased sand availability and stronger onshore winds (Clarke and Rendell, 2006), as well as cooler temperatures limiting vegetation growth and destabilising dunes (Jackson et al., 2019). Historical accounts of many settlements and agricultural land being abandoned due to wind driven sand migration throughout Europe (Clarke and Rendell, 2009), indicates that atmospheric effects on coastal communities have been always been apparent, driving a constant need for shoreline adaptation. Within the context of the present study site, the shoreline of Start Bay has likely undergone many previous sustained rotational states, evidenced by the loss of two historical settlements at opposing ends of the embayment (Figure 1), Strete Undercliff and Hallsands (Wiggins et al., 2017), within only the last 300 years. Exact dates of Strete Undercliff's formation are unclear, but it was well established by 1652 A.D. at the northern end of the embayment, likely following a sustained positive phase of cumulative NAO winters (Figure 10), driving clockwise rotation and northward sediment transport, resulting in a wide beach. It's eventual decline and demise 130 years later (1782 A.D.) followed an opposing phase of cumulative negative NAO winters, possibly driving anti-clockwise rotation and southward sediment transport. Around the same time, early 
records of the formation of Hallsands, in the southern corner of the embayment, suggest anticlockwise rotation produced a wider beach and encouraged settlement at this location, before dredging of beach shingle (Worth, 1904) and a reversal towards more positive NAO winters at the turn of the $20^{\text {th }}$ century (Wiggins et al., 2017), depleted the protective beach and the village was abandoned in 1917.

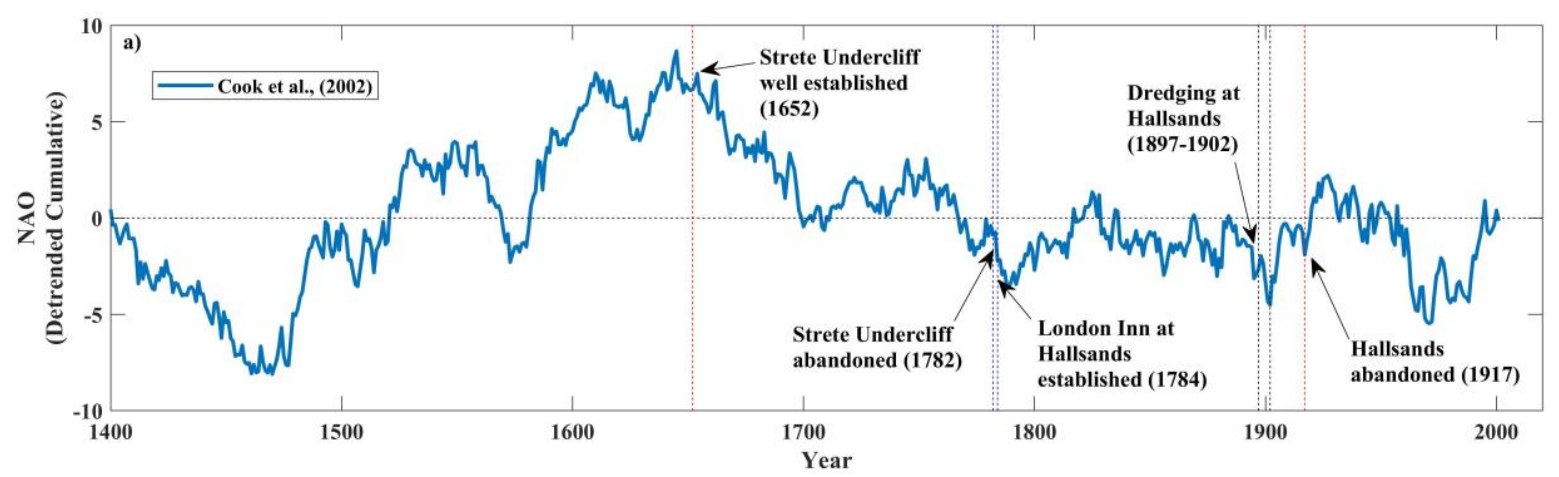

Figure 10. Detrended cumulative NAO reconstruction from Cook et al. (2002), with annotations describing the establishment and subsequent demise of two historic settlements within Start Bay, Strete Undercliff in the north, and Hallsands in the south.

The observed low frequency variations in long-term NAO suggests that sustained morphological rotations may have been occurring over substantially longer timescales in Start Bay, and much of Europe, particularly in rotation prone sites where wave climates are bi-directional.

The skill demonstrated in using combined NAO and WEPA for predicting the WDI and hence beach rotation, leads to the question of whether skilful forecasts of both indices can be obtained for either short-term (seasonal) or longer-term (multi-annual to decadal) timescales. Given that Castelle et al. (2017) have shown that NAO and WEPA are not correlated, independent forecasts of each index would need to be made well ahead of the coming winter season if the predictability of the WDI can be achieved at timescales useful to coastal managers. For example, Colman et al. (2011) made use of the NAO's positive correlation 
with wave height in the North Sea, to predict expected operational downtime of oil and gas rigs using season ahead forecasts of the NAO, made available several months in advance; however, our work presents the ability, and therefore enhanced application, of predicting the direction and magnitude of the wave power balance in a region where it significantly impacts coastal rotation and subsequent vulnerability. Improvements to seasonal NAO forecasts are currently being showcased by many authors (Baker et al., 2018; Dunstone et al., 2016; Scaife et al., 2015; Wang et al., 2017); however, hindcast predictions of the NAO over the last 100 years has shown that forecast skill may be variable, with particular weakness during sustained phases of low magnitude negative NAO winters, and better skill during the stronger, positive phases during the beginning and end of the $20^{\text {th }}$ century (Weisheimer et al., 2017). The results of the present study and several previous research efforts (Wiggins et al., 2019a, 2019b) highlight that the NAO's strong negative correlation with easterly wave events is critical in the formulation of WDI values for the present location. In this case study, skilful prediction of negative NAO winters is crucial for identifying the anti-clockwise rotations observed during increased easterly waves. WEPA has been shown to have much greater skill in predicting the occurrence of the more dominant south-westerly waves but, as yet, is largely unpredictable at the season-ahead timescale, in part due to current climate models reliance on accurate predictions of winter mean SLP, which are weaker for the areas around the UK and Ireland (Scott et al., in prep.), leading to a lack of forecast skill in areas where NAO has little influence, and WEPA is unresolved.

\section{Conclusions}

This study has shown that a combination of two major atmospheric indices significantly improves the predictive skill for a SMLR model of the bi-directional winter wave power balance (WDI), which in turn has been shown to directly control morphological beach rotation on shorter to multi-annual timescales. The model was then used to hindcast WDIPred 
using long-term records of NAO and WEPA, with the detrended cumulative values showing periodicity linked to similar fluctuations in detrended cumulative values of both indices.

Further results showed that trends in the WDIPred are mirrored in the historic records of beach rotation for this site, suggesting that beyond seasonal and event-scale rotational events, the long-term planform of this, and many similar embayments may be controlled by multidecadal to centurial scale trends in phases of atmospheric indices.

Application of this multi-index regression method suggests that the increased ability to predict climate indices some months in advance of the coming winter period, may allow for season-ahead forecasts of forthcoming wave climates, and hence potential rotational beach impacts. Practically, this would provide coastal managers with an informed forecast of likely risks in high-impact areas, enabling proactive decisions to be made regarding hard or soft engineering works within rotational sites.

The following conclusions of this study are as follows;

1. Increased skilful prediction $\left(\mathrm{R}^{2}=0.66\right)$ of the WDIPred was be obtained from a regression model comprised of two atmospheric indices, when compared to the skill of individual indices alone.

2. Modelled alongshore wave power and potential sediment flux at fixed shoreline positions were significantly correlated with observed and predicted WDI at a range of locations within the study site; suggesting that the WDI is a valid proxy for inshore sediment transport.

3. Medium term (10-year) measured beach rotation correlates with the observed and model predicted WDI record (with the exception of an individual extreme event), 
4. Longer-term records of low frequency NAO phases suggest that larger scale rotational events may have occurred at multi-centurial timescales, driving shoreline adaptation of communities in response to variations in climate indices.

\section{$\underline{\text { Acknowledgements }}$}

This research was funded by the U.K. Natural Environment Research Council, Grant Number NE/M004996/1; BLUE-coast project.

The authors would like to thank the United Kingdom Meteorological Office, The Climate Data Guide, Bruno Castelle, Guillaume Dodet and Plymouth Coastal Observatory.

\section{$\underline{\text { Data availability }}$}

WaveWatchIII datasets are available from the Climate index data for NAO is available at https://climatedataguide.ucar.edu/climate-data/hurrell-north-atlantic-oscillation-nao-indexstation-based .Climate index data for WEPA index is available at https://www.esrl.noaa.gov/psd/data/gridded/data.20thC_ReanV2.html . Topographic survey data from Plymouth University's monthly monitoring programme is archived at the British Oceanographic Data Centre (BODC), available at https://www.bodc.ac.uk/data/ .Topographic maps are available at https://digimap.edina.ac.uk/os . Historical oblique photographs are available at https://www.francisfrith.com whilst aerial photographs can be obtained from http://southwest.coastalmonitoring.org/. 
599

600

601

602

603

604

605

606

607

608

609

610

611

612

613

614

615

616

617

618

619

620

British Broadcasting Corporation, BBC, 2016. High tide causes Torcross sea wall collapse and Devon road closure. Available at: https://www.bbc.co.uk/news/uk-england-devon35558922 (Accessed: 17 October 2019).

Bacon, S., Carter, D.J.T., 1993. A connection between mean wave height and atmospheric pressure gradient in the North Atlantic. Int. J. Climatol. 13, 423-436. https://doi.org/10.1002/joc.3370130406

Baker, A., C. Hellstrom, J., Kelly, B.F.J., Mariethoz, G., Trouet, V., 2015. A composite annual-resolution stalagmite record of North Atlantic climate over the last three millennia. Sci. Rep. 5, 10307.

Baker, L.H., Shaffrey, L.C., Sutton, R.T., Weisheimer, A., Scaife, A.A., 2018. An Intercomparison of Skill and Overconfidence/ Underconfidence of theWintertime North Atlantic Oscillation in Multimodel Seasonal Forecasts. Geophys. Res. Lett. 45, 78087817. https://doi.org/10.1029/2018GL078838

Barnard, P.L., Short, A.D., Harley, M.D., Splinter, K.D., Vitousek, S., Turner, I.L., Allan, J., Banno, M., Bryan, K.R., Doria, A., Hansen, J.E., Kato, S., Kuriyama, Y., RandallGoodwin, E., Ruggiero, P., Walker, I.J., Heathfield, D.K., 2015. Coastal vulnerability across the Pacific dominated by El Niño/Southern Oscillation. Nat. Geosci. 8, 801.

Burvingt, O., Masselink, G., Russell, P., Scott, T., 2016. Beach response to consecutive extreme storms using LiDAR along the SW coast of England. J. Coast. Res. 75, 10521056. https://doi.org/10.2112/si75-211.1

Burvingt, O., Masselink, G., Scott, T., Davidson, M., Russell, P., 2018. Climate forcing of regionally-coherent extreme storm impact and recovery on embayed beaches. Mar. 
622

623

624

625

626

627

628

629

630

631

632

633

634

635

636

637

638

639

640

641

642

643

Castelle, B., Dodet, G., Masselink, G., Scott, T., 2018. Increased Winter-Mean Wave Height, Variability, and Periodicity in the Northeast Atlantic Over 1949-2017. Geophys. Res. Lett. 45, 3586-3596. https://doi.org/10.1002/2017GL076884

Castelle, B., Dodet, G., Scott, T., 2017. A new climate index controlling winter wave activity along the Atlantic coast of Europe : the West Europe Pressure Anomaly. Geophys. Res. Lett. 44, 1384-1392. https://doi.org/10.1002/2016GL072379

Chadwick, A.J., Karunarathna, H., Gehrels, W.R., Massey, A.C., O’Brien, D., Dales, D., 2005. A new analysis of the Slapton barrier beach system, UK. Proc. Inst. Civ. Eng. Marit. Eng. 158, 147-161. https://doi.org/10.1680/maen.2005.158.4.147

Clarke, M.L., Rendell, H.M., 2009. The impact of North Atlantic storminess on western European coasts: A review. Quat. Int. 195, 31-41. https://doi.org/10.1016/j.quaint.2008.02.007

Clarke, M.L., Rendell, H.M., 2006. Effects of storminess, sand supply and the North Atlantic Oscillation on sand invasion and coastal dune accretion in western Portugal. The Holocene 16, 341-355. https://doi.org/10.1191/0959683606hl932rp

Colman, A.W., Palin, E.J., Sanderson, M.G., Harrison, R.T., 2011. The Potential for Seasonal Forecasting of Winter Wave Heights in the Northern North Sea. Weather Forecast. 26 (6), 1067-1074. https://doi.org/10.1175/WAF-D-11-00017.1

Cook, E.R., D’Arrigo, R.D., Mann, M.E., 2002. A Well-Verified, Multiproxy Reconstruction of the Winter North Atlantic Oscillation. J. Clim. 15, 1754-1764.

Denbigh, A., 2017. The Slapton Line - Living with a Changing Coast. F. Stud. 1-4.

Dodet, G., Bertin, X., Taborda, R., 2010. Wave climate variability in the North-East Atlantic 
Dunstone, N., Smith, D., Scaife, A.A., Hermanson, L., Eade, R., Robinson, N., Andrews, M., Knight, J., 2016. Skilful predictions of the winter North Atlantic Oscillation one year ahead. Nat. Geosci. 9, 809. https://doi.org/https://doi.org/10.1038/ngeo2824

Faust, J., Fabian, K., Milzer, G., Giraudeau, J., Knies, J., 2016. Norwegian fjord sediments reveal NAO related winter temperature and precipitation changes of the past 2800 years. Earth Planet. Sci. Lett. 435, 84-93. https://doi.org/10.1016/j.epsl.2015.12.003

Goodall, F., 2007. Lost Devon. Birliin Publishing.

Hails, J.R., 1975. Offshore Morphology and Sediment Distribution, Start Bay, Devon. Philos. Trans. R. Soc. London. Ser. A, Math. Phys. Sci. 279, 221-228.

Harley, M.D., Turner, I.L., Kinsela, M.A., Middleton, J.H., Mumford, P.J., Splinter, K.D., Phillips, M.S., Simmons, J.A., Hanslow, D.J., Short, A.D., 2017. Extreme coastal erosion enhanced by anomalous extratropical storm wave direction. Sci. Rep. 7, 6033. https://doi.org/10.1038/s41598-017-05792-1

Hurrell, James, National Center for Atmospheric Research Staff, 2018. The Climate Data Guide: Hurrell North Atlantic Oscillation (NAO) Index (Station-based). Retrieved from. https://climatedataguide.ucar.edu/climate-data/hurrell-north-atlantic-oscillation-naoindex-station-based.

Izaguirre, C., Mendez, F.J., Menendez, M., Luceño, A., Losada, I.J., 2010. Extreme wave climate variability in southern Europe using satellite data. J. Geophys. Res. Ocean. 115. https://doi.org/10.1029/2009JC005802

Jackson, D.W.T., Costas, S., Guisado-Pintado, E., 2019. Large-scale transgressive coastal 

dune behaviour in Europe during the Little Ice Age. Glob. Planet. Change 175, 82-91. https://doi.org/10.1016/j.gloplacha.2019.02.003

Klein, A.H.D.F., Filho, L.B., Schumacher, D.H., 2002. Short-Term Beach Rotation Processes in Distinct Headland Bay Beach Systems. J. Coast. Res. 18, 442-458. https://doi.org/10.2307/4299093

Luterbacher, J., Xoplaki, E., Dietrich, D., Jones, P.D., Davies, T.D., Portis, D., Storch, H. Von, Gyalistras, D., Casty, C., Wanner, H., 2002. Extending North Atlantic Oscillation reconstructions back to 1500 . https://doi.org/10.1006/asle.2001.0044

Martínez-Asensio, A., Tsimplis, M.N., Marcos, M., Feng, X., Gomis, D., Jordà, G., Josey, S.A., 2016. Response of the North Atlantic wave climate to atmospheric modes of variability. Int. J. Climatol. 36, 1210-1225. https://doi.org/10.1002/joc.4415

Masselink, G., Castelle, B., Scott, T., Dodet, G., Suanez, S., Jackson, D., Floc'H, F., 2016. Extreme wave activity during 2013/2014 winter and morphological impacts along the Atlantic coast of Europe. Geophys. Res. Lett. 43, 2135-2143. https://doi.org/10.1002/2015GL067492

Masselink, G., Scott, T., Poate, T., Russell, P., Davidson, M., Conley, D., 2015. The extreme 2013/2014 winter storms: hydrodynamic forcing and coastal response along the southwest coast of England. Earth Surf. Process. Landforms 41, 378-391. https://doi.org/10.1002/esp.3836

May, V.J., Hansom, J.D., 2003. Hallsands, Coastal Geomorphology of Great Britain, Geological Conservation Review Series.

McCarroll, R.J., Masselink, G., Valiente, N.G., Wiggins, M., Scott, T., Conley, D.C., King, E. V., 2020. Impact of a headland-associated sandbank on shoreline dynamics. 
691

692

693

694

695

696

697

698

699

700

701

702

703

704

705

706

707

708

709

710

711

712

McCarroll, R.J., Masselink, G., Wiggins, M., Scott, T., Billson, O., Conley, D.C., Valiente, N.G., Sciences, M., Circus, D., Hill, B., 2019. High-efficiency gravel longshore sediment transport and headland bypassing over an extreme wave event 1-19. https://doi.org/10.1002/esp.4692

Nicholls, R.J., Marinova, N., Lowe, J.A., Brown, S., Vellinga, P., de Gusmao, D., Hinkel, J., Tol, R.S.J., 2011. Sea-level rise and its possible impacts given a "beyond $4{ }^{\circ} \mathrm{C}$ world" in the twenty-first century. Philos. Trans. R. Soc. A Math. Phys. Eng. Sci. 369, 161-181. https://doi.org/10.1098/rsta.2010.0291

Plomaritis, T.A., Benavente, J., Laiz, I., Del Río, L., 2015. Variability in storm climate along the Gulf of Cadiz: the role of large scale atmospheric forcing and implications to coastal hazards. Clim. Dyn. 45, 2499-2514. https://doi.org/10.1007/s00382-015-2486-4

Ranasinghe, R., McLoughlin, R., Short, A.D., Symonds, G., 2004. The Southern Oscillation Index, wave climate, and beach rotation. Mar. Geol. 204, 273-287. https://doi.org/10.1016/S0025-3227(04)00002-7

Robinson, A.H.W., 1961. The Hydrography of Start Bay and Its Relationship to Beach Changes at Hallsands. Geogr. J. 127, 63-77. https://doi.org/10.2307/1793197

Ruiz de Alegria-Arzaburu, A., Masselink, G., 2010. Storm response and beach rotation on a gravel beach, Slapton Sands, U.K. Mar. Geol. 278, 77-99. https://doi.org/10.1016/j.margeo.2010.09.004

Scaife, A.A., Yu Karpechko, A., Baldwin, M., Brookshaw, A., Butler, A., Eade, R., Gordon, M., Maclachlan, C., Martin, N., Dunstone, N., Smith, D., 2015. Seasonal winter forecasts and the stratosphere. Atmos. Sci. Lett. 17, 51-56. 
Scott, T., Masselink, G., Hare, T.O., Saulter, A., Poate, T., Russell, P., Davidson, M., Conley, D., 2016. The extreme 2013 / 2014 winter storms : Beach recovery along the southwest coast of England. Mar. Geol. 382, 224-241. https://doi.org/10.1016/j.margeo.2016.10.011

Scott, T., Masselink, G., McCarroll, R.J., Castelle, B., Dodet, G., Saulter, A., Scaife, A.A.,

Splinter, K.D., Davidson, M.A., Golshani, A., Tomlinson, R., 2012. Climate controls on longshore sediment transport. Cont. Shelf Res. 48, 146-156. https://doi.org/10.1016/j.csr.2012.07.018

Stranack, D., 2017. The Lost Village of Undercliff, Blackawton and Strete History Group.

Thomas, T., Phillips, M.R., Williams, a T., 2013. A Centurial Record of Beach Rotation. J. Coast. Res. 594-599. https://doi.org/10.2112/SI65-101.1

Trouet, V., Esper, J., Baker, A., Scourse, J., 2009. Persistent Positive North Atlantic Oscillation Mode Dominated the Medieval Climate Anomaly Persistent Positive North Atlantic Oscillation Mode Dominated the Medieval Climate Anomaly. https://doi.org/10.1126/science.1166349

Trouet, V., Scourse, J.D., Raible, C.C., 2012. North Atlantic storminess and Atlantic Meridional Overturning Circulation during the last Millennium: Reconciling contradictory proxy records of NAO variability. Glob. Planet. Change 84-85, 48-55. https://doi.org/10.1016/j.gloplacha.2011.10.003

UKHO, U.K.H.O., 2013. INSPIRE Portal \& Bathymetry DAC [WWW Document]. Available 

at. http//aws2.caris.com/ukho/mapViewer/map.action.

737

USACE, 2002. Shore Protection Manual. Government Printing Office, Washington, D.C.

van Rijn, L.C., 2014. A simple general expression for longshore transport of sand, gravel and shingle. Coast. Eng. 90, 23-39. https://doi.org/https://doi.org/10.1016/j.coastaleng.2014.04.008

Vos, K., Harley, M.D., Splinter, K.D., Simmons, J.A., Turner, I.L., 2019. Sub-annual to multi-decadal shoreline variability from publicly available satellite imagery. Coast. Eng. 150, 160-174. https://doi.org/10.1016/j.coastaleng.2019.04.004

Wang, L., Ting, M., Kushner, P.J., 2017. A robust empirical seasonal prediction of winter NAO and surface climate. Sci. Rep. 7, 279. https://doi.org/10.1038/s41598-017-00353-y

Waterhouse, R., 2009. Blackawton \& Strete heritage appraisal: an archaeological history. South Hams District Council, Totnes.

Weisheimer, Antje, Schaller, N., Reilly, C.O., Macleod, A., Palmer, T., Centre, E., Weather, M., Ecmwf, F., Weisheimer, A, 2017. Atmospheric seasonal forecasts of the twentieth century : multi-decadal variability in predictive skill of the winter North Atlantic Oscillation ( NAO ) and their potential value for extreme event attribution. Q. J. R. Meteorol. Soc. 143, 917-926. https://doi.org/10.1002/qj.2976

Wiggins, M., Scott, T., Masselink, G., Russell, P., Castelle, B., Dodet, G., 2017. The role of multi-decadal climate variability in controlling coastal dynamics: re-interpretation of the “Lost Village of Hallsands,” in: Proceedings Coastal Dynamics 2017. pp. 96-107.

Wiggins, M., Scott, T., Masselink, G., Russell, P., McCarroll, R.J., 2019a. Coastal embayment rotation : Response to extreme events and climate control, using full embayment surveys. Geomorphology 327, 385-403. 
760 Wiggins, M., Scott, T., Masselink, G., Russell, P., Valiente, N.G., 2019b. RegionallyAtmospheric Forcing. J. Mar. Sci. Eng. 7, 116.

763 Worth, R.H., 1904. Hallsands and Start Bay. Devonsh. Assoc. 36, 302-346. 